\title{
Policy statement from the Society for Healthcare Epidemiology of America (SHEA): Only medical contraindications should be accepted as a reason for not receiving all routine immunizations as recommended by the Centers for Disease Control and Prevention
}

\author{
David J. Weber MD, MPH ${ }^{1}$, Thomas R. Talbot MD, MPH${ }^{2}$, Allison Weinmann MBBS 3 , Trini Mathew MD, MPH \\ Emily Heil PharmD ${ }^{5}$, Edward Stenehjem MD, MSC $^{6}$, Robert Duncan MD, MPH ${ }^{7}$, Alan Gross PharmD ${ }^{8}$, \\ Patricia Stinchfield APRN CNP ${ }^{9}$, Christopher Baliga $\mathrm{MD}^{10}$, Jamie Wagner PharmD ${ }^{11}$, William Schaffner MD ${ }^{12}$, \\ Kelly Echevarria PharmD, BCPS, AQ-ID, BCIDP ${ }^{13}$ and Marci Drees MD, MS, DTMH ${ }^{14}$ on behalf of the Society for \\ Healthcare Epidemiology of America (SHEA) \\ ${ }^{1}$ Department of Infectious Diseases, University of North Carolina at Chapel Hill, Chapel Hill, North Carolina, ${ }^{2}$ Department of Medicine, Vanderbilt University \\ School of Medicine, Nashville, Tennessee, ${ }^{3}$ Division of Infectious Diseases, Henry Ford Health System, Detroit, Michigan, ${ }^{4}$ Infectious Diseases and International \\ Medicine, Beaumont Hospital, Royal Oak, Royal Oak, Michigan, ${ }^{5}$ Department of Pharmacy Practice and Science, University of Maryland School of Pharmacy, \\ Baltimore, Maryland, ${ }^{6}$ Office of Patient Experience and Division of Infectious Diseases, Intermountain Healthcare, Murray, Utah, ${ }^{7}$ Division of Infectious Disease, \\ Lahey Hospital \& Medical Center, Burlington, Massachusetts, ${ }^{8}$ Department of Pharmacy Practice, University of Illinois at Chicago College of Pharmacy, Chicago, \\ Illinois, ${ }^{9}$ Childrens Hospitals and Clinics of Minnesota, St. Paul, Minnesota, ${ }^{10}$ Section of Infectious Diseases, Department of Medicine, Virginia Mason Medical \\ Center, Seattle, Washington, ${ }^{11}$ Department of Pharmacy Practice, University of Mississippi School of Pharmacy, Jackson, Mississippi, ${ }^{12}$ Department of Health \\ Policy, Vanderbilt University School of Medicine, Nashville, Tennessee, ${ }^{13}$ VHA Pharmacy Benefits Management, South Texas Veterans Health Care System, San \\ Antonio, Texas and ${ }^{14}$ Christiana Care Health System, Newark, Delaware
}

\section{Summary}

SHEA endorses adhering to the recommendations by the CDC and ACIP for immunizations of all children and adults. All persons providing clinical care should be familiar with these recommendations and should routinely assess immunization compliance of their patients and strongly recommend all routine immunizations to patients. All healthcare personnel (HCP) should be immunized against vaccine-preventable diseases as recommended by the CDC/ACIP (unless immunity is demonstrated by another recommended method). SHEA endorses the policy that immunization should be a condition of employment or functioning (students, contract workers, volunteers, etc) at a healthcare facility. Only recognized medical contraindications should be accepted for not receiving recommended immunizations.

(Received 2 July 2020; accepted 11 July 2020; electronically published 17 September 2020)

Immunization against vaccine-preventable diseases as recommended by the US Centers for Disease Control and Prevention/ Advisory Committee on Immunization Practices (CDC/ACIP) is essential to improving public health and reducing healthcareassociated spread of these infections. In particular, all healthcare personnel should be immune to vaccine-preventable diseases unless there is a medical contraindication to immunization.

\section{Policy Statements}

1. SHEA endorses adhering to all current child and adult CDC/ ACIP recommendations for immunizations of all children and

Author for correspondence: David J. Weber, E-mail: dweber@unch.unc.edu Cite this article: Weber DJ, Talbot TR. (2021). Policy statement from the Society for Healthcare Epidemiology of America (SHEA): Only medical contraindications should be accepted as a reason for not receiving all routine immunizations as recommended by the Centers for Disease Control and Prevention. Infection Control \& Hospital Epidemiology, 42: 1-5, https://doi.org/10.1017/ice.2020.342 adults. SHEA strongly encourages all HCP to recommend all routine immunizations to patients per the most recent CDC-recommended immunization schedules.

Rationale: Vaccines are a proven effective and safe public health measure that prevents many infectious diseases affecting children, adolescents, and adults. Vaccines have eradicated (eg, smallpox and polio types 2 and 3) or eliminated (eg, measles and rubella) many infectious diseases that were once common in the United States. Vaccines have dramatically reduced the incidence of hospitalization and death for many infectious agents still circulating in the United States (eg, invasive Haemophilus influenzae type B, influenza, varicella, pertussis, hepatitis A, and hepatitis B). Other benefits of vaccines include prevention of colonization (conjugate vaccines in childhood; meningococcal A, C, W, Y; $H$. influenzae, pneumococcal); postexposure prophylaxis (eg, rabies, measles, varicella, hepatitis A, hepatitis B), outbreak control (eg, measles, mumps, invasive meningococcal infections), amelioration of illness (eg, influenza, varicella), prevention of disease 
Table 1. Impact of Immunization on Selected Vaccine-Preventable Diseases, United States ${ }^{\text {a }}$

\begin{tabular}{|c|c|c|c|}
\hline Disease & Maximum No. of Cases (Year) & No. of Cases, 2018 & $\%$ Reduction \\
\hline Diphtheria & $206,939(1921)$ & 1 & 99.99 \\
\hline Invasive Haemophilus influenzae type B ( $<5$ yo) & $20,000(1984)$ & 38 & 99.81 \\
\hline Measles & $894,135(1941)$ & 375 & 98.34 \\
\hline Mumps & $152,209(1968)$ & 2,515 & 99.13 \\
\hline Meningococcal ACWY & $330(2008)$ & 100 & 69.70 \\
\hline Pertussis & $265,269(1934)$ & 15,609 & 94.12 \\
\hline Polio & $21,269(1952)$ & 0 & 100.00 \\
\hline Rubella & $57,686(1969)$ & 4 & 99.99 \\
\hline Rubella (congenital) & $20,000(1964-65)$ & 0 & 100.00 \\
\hline Tetanus & $601(1948)$ & 23 & 96.17 \\
\hline
\end{tabular}

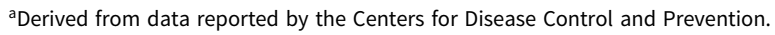

reactivation (eg, zoster), reduction in antibiotic resistance (eg, conjugate pneumococcal vaccine in children), indirect protection (herd immunity, community protection, eg, measles, mumps, varicella, HPV, hepatitis A, polio), and decreased use of medical resources allowing funds to be redirected to other health promotion programs.

Immunization is considered by the CDC as one of the " 10 greatest public health achievements in the United States, 1900-1999."' The historical disease and death burden for vaccine-preventable diseases in the United States was substantial, and vaccines have dramatically reduced the prevalence of infection (Table 1). In 2011 , the CDC also listed immunization as one of the " 10 great public health achievements in the United States, 2001-2010." They noted that during the first decade of the 21 st century in the United States, there were substantial declines in cases, hospitalizations, deaths, and healthcare costs associated with vaccine-preventable diseases. Examples of vaccine impact included the prevention of an estimated 211,000 serious pneumococcal infections and 13,000 deaths (2000-2008) after the introduction of the pneumococcal conjugate vaccine and of an estimated 40,000-60,000 rotavirus hospitalizations each year after the introduction of rotavirus immunization in $2006 .^{2}$

The success of vaccines in improving the health of the public is worldwide. The World Health Organization (WHO) estimates that "vaccines prevented at least 10 million deaths between 2010 and 2015, and many millions more lives were protected from illness."3 Furthermore, the WHO estimates that immunization currently prevents 2-3 million deaths every year and that an additional 1.5 million deaths could be avoided if global vaccine coverage improves. 4

Largely due to decreasing vaccine coverage, in 2019 the United States has experienced the greatest number of measles cases (preliminary count, 1,282 persons) since $1992 .{ }^{5}$ Most cases occur in unvaccinated persons. Worldwide measles vaccination resulted in a 73\% decrease in measles deaths between 2000 and 2018, but low coverage led to large outbreaks in multiple regions (eg, Democratic Republic of Congo, Samoa, Ukraine). Cases have swelled to a 10 -year peak, causing many deaths, ${ }^{6}$ thus posing a risk of continuing importation of measles into the United States. Despite a dramatic decrease in mumps in the United States following the introduction of the vaccine in 1967, since 2006 there have been several increases in cases and outbreaks approximately every 5 years. These also have been triggered by importations from abroad.
As noted by the CDC and vaccine experts, the benefits of immunization greatly outweigh the risks. ${ }^{7}$ Although vaccines may be associated with local reactions such as pain and erythema at the injection site, serious adverse events are exceedingly rare. Worldwide vaccine misinformation stems, in part, from a notorious paper that erroneously linked autism to the mumps, measles, and rubella $(\mathrm{MMR})$ vaccine that was retracted for fraud. Multiple studies have found no causal link between immunization and autism. ${ }^{7}$ A recent study of 657,461 Danish children confirmed that MMR immunization does not confer an increased risk of autism. ${ }^{8}$ Another myth arose over concern that thimerosal, a preservative containing ethyl mercury that was included in vaccines in the past, could cause autism or lead to neurodevelopmental problems in infants. However, multiple studies have demonstrated no link between thimerosal exposure and adverse outcomes such as autism or abnormal neuropsychological functioning. ${ }^{7,9,10}$ Nevertheless, to prevent these unfounded concerns from discouraging vaccination, thimerosal has been removed from all routine childhood vaccines except multidose vials of influenza vaccine.

Unfortunately, concerns regarding vaccine safety have led, in part, to decreasing vaccine coverage in many locations in the United States and the world. The World Health Organization, listed "vaccine hesitancy" as one of the "10 threats to global health in 2019," stating that vaccine hesitance (the reluctance or refusal to vaccinate despite the availability of vaccines) threatens to reverse progress made in tackling vaccine-preventable diseases. ${ }^{11}$ Therefore, HCP should be aware of demonstrated vaccine adverse events, vaccine contraindications and precautions, and vaccine myths, and they should effectively communicate the fallacies of such myths. ${ }^{12,13}$

Overall, HCP remain the most trusted advisors and influencers of immunization decisions. Therefore, HCP should routinely assess their patient's immunization status and strongly recommend that their patients receive all vaccines recommended by the CDC/ACIP. All HCP should be familiar with indications for immunization $^{14}$ and evidence-based interventions that improve vaccine coverage (eg, standing orders, patient reminders/recall for vaccination, and provider reminders). ${ }^{12,15}$ Furthermore, HCP should be aware of common concerns regarding immunization (eg, vaccine will cause disease due to antigen in the vaccine, lack of effectiveness, and safety), and they should be prepared to allay these concerns. Videos such as those available from the American Academy of Pediatrics (https://www.aap.org/en-us/advocacy-and-policy/aaphealth-initiatives/immunizations/Pages/Communication-Aids. 
Table 2. Proof of Immunity to Vaccine-Preventable Diseases Recommended for Healthcare Personnel by the Centers for Disease Control and Epidemiology

\begin{tabular}{|c|c|c|c|c|c|}
\hline Vaccine & Birth Before 1957 & Physician Diagnosis & Positive Serology & Self-Report & Documented Vaccination \\
\hline Mumps & $Y_{e s}{ }^{a}$ & Yes $^{b}$ & Yes & No & Yes \\
\hline Measles & Yes $^{\mathrm{a}}$ & Yes $^{b}$ & Yes & No & Yes \\
\hline Rubella & Yes $^{a}$ & No & Yes & No & Yes \\
\hline Varicella & No & Yes & Yes & No & Yes \\
\hline Hepatitis $B^{c}$ & No & - & $\geq 10 \mathrm{MIU} / \mathrm{mL}^{\mathrm{d}}$ & No & Yes \\
\hline Influenza & No & No & No & No & Yes \\
\hline
\end{tabular}

${ }^{a}$ Consider 2-dose series at least 4 weeks apart for measles or mumps or 1 dose for rubella.

${ }^{b}$ Requires laboratory confirmation of infection.

'Must be offered to healthcare personnel with potential exposure to blood or potentially contaminated body fluids.

${ }^{\mathrm{d}}$ Titer should be obtained only after an appropriate series of hepatitis B immunizations.

aspx\#Risk) may aid clinicians in having prepared discussion points to reassure patients about vaccine safety and to allay common concerns.

2. SHEA strongly endorses robustly enforced immunization requirements for all attendees and staff of childcare and educational facilities, such as primary and secondary schools, and colleges/universities. Only recognized medical contraindications documented by a clinician should be accepted as a reason for not receiving recommended immunizations.

Rationale: Immunization of all children and adults reduces the vaccinated person's risk of morbidity and mortality from vaccine preventable diseases. In group settings such as day care and schools, it also reduces the risk of disease transmission to persons who are not immune because of a contraindication to immunization (eg, live virus vaccine for immunocompromised persons) or vaccine failure, and it is especially important for persons who are at higher risk for morbidity or mortality from a vaccine-preventable disease. Schools, especially high schools and colleges, are often the setting for outbreaks of vaccine-preventable diseases such as mumps, measles, influenza, and invasive meningococcal infections.

Because SHEA is also concerned with protecting HCP and patients from vaccine-preventable diseases, a benefit of improved immunization of the public would be decreased risk to HCP and patients. Both patients and visitors have been demonstrated to introduce vaccine-preventable diseases into hospitals and healthcare facilities leading to outbreaks among patients and HCP. ${ }^{16}$ These outbreaks have led to substantial morbidity and occasional mortality among patients and HCP. High vaccine coverage of the public as a part of a comprehensive infection prevention program will minimize the introduction of vaccinepreventable diseases into healthcare facilities. Importantly, immunization is the preferred method of control for the following reasons: (1) Persons with many vaccine-preventable diseases may be infectious prior to the development of symptoms (eg, influenza, measles, mumps, rubella, varicella). ${ }^{17}$ (2) Persons who are asymptomatic may transmit several vaccine-preventable diseases (eg, influenza, hepatitis B). (3) Many vaccine-preventable diseases may lead to substantial numbers of exposures in healthcare facilities because they are transmitted by the droplet route (eg, mumps, rubella, pertussis, influenza) or by the airborne route (eg, varicella, measles). (4) Patients with vaccine-preventable diseases often seek care in healthcare facilities, thereby exposing other patients who cannot be immunized and/or are at high risk for morbidity and mortality (eg, immunocompromised, pregnant).

SHEA endorses the policy statements of the following professional organizations: American Academy of Family Physicians (AAFP), ${ }^{18}$ American Academy of Pediatrics (AAP), ${ }^{19}$ American Medical Association (AMA), ${ }^{20}$ American College of Obstetricians and Gynecologists (ACOG), ${ }^{21}$ American College of Physicians (ACP), ${ }^{22}$ American Nurses Association (ANA), ${ }^{23}$ Infectious Diseases Society of America (IDSA), ${ }^{24}$ Pediatric Infectious Diseases Society (PIDS ${ }^{25}$ and the National Association of Pediatric Nurse Practitioners (NAPNAP). ${ }^{26}$

3. All HCP should be immune to vaccine preventable diseases as recommended by the CDC/ACIP. SHEA endorses that immunity should be a condition of employment or functioning in their role as HCP (eg, students, contract workers, volunteers, etc) in all healthcare settings. Only recognized medical contraindications should be accepted for not receiving recommended immunizations.

Rationale: HCP have introduced or propagated infections leading to outbreaks in healthcare facilities. ${ }^{16}$ This has resulted in substantial morbidity and even mortality among patients and HCP. Thus, all HCP should have appropriately documented immunizations (unless immunity has been demonstrated by another CDC/ ACIP recommended method) to measles, mumps, rubella, influenza, and varicella unless there is a medical contraindication to immunization (Table 2) ${ }^{27} \mathrm{HCP}$ who may have exposure to blood or other potentially infectious body fluids should be immunized against hepatitis $\mathrm{B}$ unless there is a medical contraindication to immunization as HCP are at risk for the acquisition of hepatitis $B$ via percutaneous or mucous membrane exposures to blood or other potentially infectious body fluids. ${ }^{27}$ Importantly, $>40$ reports of HCP-to-patient transmission of hepatitis B have been reported. ${ }^{28-30} \mathrm{HCP}$ who opt out of hepatitis B immunization must have a signed declination on file per the US Occupational and Health Administration (https://www.osha.gov/SLTC/etools/hospital/ hazards/bbp/declination.html). Microbiologists working a healthcare facility who are routinely exposed to isolates of Neisseria meningitidis should be immune to Neisseria meningitidis types A, C, W, Y, and B. ${ }^{27,31}$ Exclusion of ill HCP, while fundamentally important, is not an adequate practice alone because exclusion will not protect patients from transmission of vaccine-preventable diseases while $\mathrm{HCP}$ are in the incubating phase of disease and during asymptomatic infection. 
SHEA endorses the broad definition of HCP used by CDC which states "HCP refers to all paid and unpaid persons serving in healthcare settings who have the potential for direct or indirect exposure to patients or infectious materials, including body substances (eg, blood, tissue, and specific body fluids); contaminated medical supplies, devices, and equipment; contaminated environmental surfaces; or contaminated air." ${ }^{32}$ SHEA also endorses the definition of healthcare facilities used by CDC which "refers to places where healthcare is delivered and includes, but is not limited to, acute-care facilities, long-term acute-care facilities, inpatient rehabilitation facilities, nursing homes and assisted living facilities, home healthcare, vehicles where healthcare is delivered (eg, mobile clinics), and all types of outpatient facilities, such as dialysis centers, physician offices, and others." ${ }^{32}$

The principle of "first do no harm" can be found in the writings of Hippocrates and the Medical School of Cos. ${ }^{33,34}$ HCP have a duty to protect their patients from acquisition of preventable infections that can be transmitted by HCP. Therefore, receipt of recommended vaccines by HCP should be a condition of employment or education in a healthcare facility unless the provider has a medical contraindication. Only medical contraindications recognized by the CDC/ACIP or by the US Food and Drug Administration (as listed in the package insert for the particular vaccine) should be accepted by occupational health services. ${ }^{12}$

The SHEA has previously stated, "For the safety of both patients and HCP, SHEA endorses a policy in which annual influenza vaccination is a condition of both initial and continued HCP employment and/or professional privileges." ${ }^{35}$ In 2013, SHEA also partnered with IDSA and PIDS to extend that endorsement to all vaccines recommended by the CDC/ACIP for HCP. In 2018, the SHEA endorsed the "Call To Action; Improving Healthcare Personnel Immunization Rates" by the National Foundation for Infectious Diseases, ${ }^{36}$ a position that the SHEA confirms with the current policy statement. Requiring appropriate immunizations as a condition of employment has been demonstrated to be the most effective strategy for maximizing immunization compliance among HCP. ${ }^{37}$

Acknowledgments. The following SHEA members drafted this statement: David J. Weber (Co-Chair), Thomas R. Talbot (Co-Chair), Cristopher Baliga, Marcie Drees, Robert Duncan, Kelly Echevarria, Alan Gross, Emily Heil, Trini Mathew, William Schaffner, Eddie Stenehjem, Patricia Stinchfield, Jamie Wagner, Allison Weinman.

Endorsements. The following organizations endorse this statement: APIC Association for Professionals in Infection Control and Epidemiology; HIV Medicine Association; Infectious Diseases Society of America; National Foundation for Infectious Diseases; and the Society of Infectious Diseases Pharmacists.

\section{References}

1. Centers for Disease Control and Prevention. Ten great public health achievements, United States, 1900-1999. Morbid Mortal Wkly Rept 1999;48:241-243.

2. Centers for Disease Control and Prevention. Ten great public health achievements, United States, 2001-2010. Morbid Mortal Wkly Rept 2011;60:619-623.

3. The power of vaccines: still not fully utilized. World Health Organization website. https://www.who.int/publications/10-year-review/vaccines/en/. Accessed December 1, 2019.

4. Immunization. World Health Organization website. https://www.who.int/ news-room/facts-in-pictures/detail/immunization. Published December 5, 2019. Accessed December 9, 2019.
5. Measles cases and outbreaks. Centers for Disease Control and Prevention website. https://www.cdc.gov/measles/cases-outbreaks.html. Updated June 5, 2020. Accessed December 9, 2019.

6. Measles. World Health Organization website. https://www.who.int/newsroom/fact-sheets/detail/measles. Published December 5, 2019. Accessed December 9, 2019.

7. Spencer JP, Trondsen Pawlowski RH, Thomas S. Vaccine adverse events: separating myth from reality. Am Fam Physician 2017;95:786-794.

8. Hviid A, Hansen JV, Frisch M, Melbye M. Measles, mumps, rubella vaccination and autism: a nationwide cohort study. Ann Intern Med 2019;170:513-520.

9. Thimerosal—questions and answers. World Health Organization website. https://www.who.int/immunization/newsroom/thiomersal_questions_and_ answers/en/. Published October 2011. Accessed January 20, 2020.

10. Thimerosal in vaccines. Centers for Disease Control and Prevention website. https://www.cdc.gov/vaccinesafety/concerns/thimerosal/index.html. Updated October 2015. Accessed January 20, 2020.

11. Ten threats to global health in 2019. World Health Organization website. https://www.who.int/news-room/feature-stories/ten-threats-to-globalhealth-in-2019. Published 2019. Accessed January 20, 2020.

12. Ezeanolue E, Harriman K, Hunter P, Kroger A, Pellegrine C. General best practice guidelines for immunization. Best practice guidance of the Advisory Committee on Immunization Practices (ACIP). Centers for Disease Control and Prevention website. https://www.cdc.gov/vaccines/ hcp/acip-recs/general-recs/downloads/general-recs.pdf. Accessed February 8, 2020.

13. Common questions about vaccines. Centers for Disease Control and Prevention website. https://www.cdc.gov/vaccines/parents/FAQs.html? CDC_AA_refVal=https\%3A\%2F\%2Fwww.cdc.gov\%2Fvaccines\%2Fparents \%2Fparent-questions.html. Updated May 2019. Accessed December 3, 2019.

14. Ten reasons to get vaccinated. National Foundation for Infectious Diseases website. https://www.nfid.org/immunization/10-reasons-to-get-vaccinated/. Updated November 2019. Accessed December 3, 2019.

15. Cataldi JR, Kerns ME, O'Leary ST. Evidence-based strategies to increase vaccination uptake: a review. Curr Opin Pediatr 2020;32:151-159.

16. Weber DJ, Rutala WA. Vaccine for healthcare workers. In: Plotkin SA, Orenstein WA, Offit PA (eds). Vaccines, 5th edition. New York: Saunder Elsevier; 2008:1453-1478.

17. Heyman DL, ed. Control of Communicable Diseases Manual, 20th edition. Washington DC: American Public Health Association Press; 2015.

18. Immunization exemptions. American Academy of Family Practice (AAFP) website. https://www.aafp.org/about/policies/all/immunizations-exemptions. html. Published September 2015. Accessed December 1, 2019.

19. American Academy of Pediatrics (AAP). Medical versus nonmedical immunization exemptions for child care and school attendance. American Academy of Family Practice (AAFP) website. https://www. aafp.org/about/policies/all/immunizations-exemptions.html. Published September 2015. Accessed December 1, 2019.

20. AMA supports tighter limitations on immunization opt outs. American Medical Association (AMA) website. https://www.ama-assn.org/presscenter/press-releases/ama-supports-tighter-limitations-immunization-opt-outs. Published June 2015. Accessed December 1, 2019.

21. Vaccines and nonmedical exemptions. American College of Obstetrics and Gynecology (ACOG) website. www.acog.org/-/media/Statements-ofPolicy/Public/99VacineExemptions.pdf?dmc=1\&ts=20190919T1728130898. Accessed December 1, 2019.

22. State immunization laws should eliminate non-medical exemptions say internists. American College of Physicians (ACP) website. www.acponline. org/acp-newsroom/state-immunization-laws-should-eliminate-non-medicalexemptions-say-internists. Published July 2015. Accessed December 1, 2019.

23. American Nurses Association. American Nurses Association Takes Action on Critical Public Health Issues. https://www.nursingworld.org/news/newsreleases/2019-news-releases/american-nurses-association-takes-action-oncritical-public-health-issue. Accessed December 1, 2019.

24. Infectious Disease Society of America (IDSA). Infectious Diseases Society of America's policy on state immunization mandates. American Medical 
Association website. https://www.ama-assn.org/press-center/press-releases/ ama-supports-tighter-limitations-immunization-opt-outs. Published June 8, 2015. Accessed December 1, 2019.

25. Infectious Diseases Society of America's policy on state immunization mandates. Pediatric Infectious Disease Society (PIDS) website. www.pids.org/ impages/docs/Advocacy/Pediatric_Infectious_Diseases_Society_Position_on_ Non.pdf. Accessed December 1, 2019.

26. National Association of Pediatric Nurse Practitioners. Position statement on immunizations. J Pediatr Health Care 2015;29:PA11-A12.

27. Centers for Disease Control and Prevention. Immunization of health-care personnel: recommendations of the advisory committee on immunization practices. MMWR Recommend Rept 2011;60:1-45.

28. Weber DJ, Hoffmann KK, Rutala WA. Management of the healthcare worker infected with human immunodeficiency virus: lessons from nosocomial transmission of hepatitis B virus. Infect Control Hosp Epidemiol 1991;12:625-630.

29. Bell DM, Shapiro CN, Ciesielski CA, Chamberland ME. Preventing bloodborne pathogen transmission from healthcare workers to patients. The CDC perspective. Surg Clin North Am 1995;75:1189-203.

30. Henderson DK, Dembry L, Fishman NO, et al. SHEA guideline for management of healthcare workers who are infected with hepatitis B virus, hepatitis $\mathrm{C}$ virus, and/or human immunodeficiency virus. Infect Control Hosp Epidemiol 2010;31:203-232.

31. Centers for Disease Control and Prevention. Use of serogroup B meningococcal vaccines in persons aged $\geq 10$ years at increased risk for serogroup B meningococcal disease: recommendations of the Advisory Committee on Immunization Practices, 2015. Morbid Mortal Wkly Rept 2015;64:608-612.

32. Infection control in healthcare personnel: infrastructure and routine practices for occupational infection prevention and control services. Centers for Disease Control and Prevention website. https://www.cdc.gov/infectioncontrol/ guidelines/healthcare-personnel/introduction.html. Published 2019. Accessed January 10, 2020.

33. Askitopoulou H, Vgontzas AN. The relevance of the Hippocratic oath to the ethical and moral values of contemporary medicine. Part I: The Hippocratic oath from antiquity to modern times. Eur Spine $J$ 2018;27:1481-1490.

34. Askitopoulou H, Vgontzas AN. The relevance of the Hippocratic oath to the ethical and moral values of contemporary medicine. Part II: Interpretation of the Hippocratic oath-today's perspective. Eur Spine J 2018;27:1491-1500.

35. Talbot TR, Babcock H, Caplan AL, et al. Revised SHEA position paper: influenza vaccination of healthcare personnel. Infect Control Hosp Epidemiol 2010;31:987-995.

36. Call to action: improving healthcare personnel immunization rates, March 2018. National Foundation for Infectious Diseases website. https://www. nfid.org/publications/improving-healthcare-personnel-immunization-ratesmarch-2018/. Published March 2018. Accessed January 10, 2020.

37. Wang TL, Jing L, Bocchini JA Jr. Mandatory influenza vaccination for all healthcare personnel: a review on justification, implementation and effectiveness. Curr Opin Pediatr 2017;29:606-615. 